\title{
O IMAGINÁRIO DA PALAVRARIA: UM CAMINHO PARA O DOCENTE VIVENCIAR A ESFERA ARTISTICA QUE A ARQUITETURA PROPOE
}

THE IMAGINARIUM WORDS: A PATH TO THE PROFESSOR EXPERIENCE THE ARTISTIC SPHERE PROPOSED BY ARCHITECTURE

\author{
EL IMAGINARIO DE PALAVRARIA: UN CAMINO PARA EL DOCENTE VIVIR LA \\ ESFERA ARTÍSTICA QUE LA ARQUITECTURA PROPONE
}

\author{
Josicler Orbem Alberton* \\ josicler.alberton@gmail.com \\ Valeska Fortes de Oliveira** \\ guiza@terra.com.br
}

Tania Micheline Miorando***

\begin{abstract}
tmiorando@gmail.com
REVISTA PEDAGÓGICA

Revista do Programa de Pós-graduação em Educação da Unochapecó | ISSN 1984-1566

Universidade Comunitária da Região de Chapecó | Chapecó-SC, Brasil Como referenciar este artigo: ALBERTON, J. O.; OLIVEIRA, V. F.; MIORANDO, T. M. O imaginário da palavraria: um caminho para o docente vivenciar a esfera artística que a Arquitetura propõe. Revista Pedagógica, Chapecó, v. 18, n. 38, p. 170-183, maio/ago. 2016. DOI: http://dx.doi.org/10.22196/rp.v18i38.3393
\end{abstract}

RESUMO: A Arquitetura constitui-se do diálogo entre arte e técnica. Embora o saber sensível permeie todos os atos projetuais, no fazer docente a ênfase pelo saber técnico é indiscutível e, muitas vezes, inquestionável. Neste sentido, o presente artigo argumenta sobre a importância da arte no ato da criação arquitetônica no ambiente universitário - sob o viés do Imaginário Social (CASTORIADIS, 1982) e seus desdobramentos no fazer do docente arquiteto. Através da apresentação de três exercícios didáticos objetiva problematizar a temática em busca de um percurso mais sensível para o ensino e a aprendizagem de alunos e professores. O ambiente de investigacão dentro do Curso de Arquitetura e Urbanismo, sob o viés do Imaginário Social, contribuiu para o aumento da autoconfiança dos alunos e docentes além de possibilitar uma interação criativa entre professores e alunos.

Palavras-chave: Formação Docente. Arquitetura. Imaginário Social. Processos Criativos. Ensino.

ABSTRACT: The architecture is constituted of dialogue between art and technique. Although the sensitive knowledge exists in all projective acts, in education of the architecture the emphasis on technical knowledge is indisputable and often un questioned. Thus, this article argues about the art importance in the act of the architecture creation - in the university environment - with reference to the Social Imaginary (CASTORIADIS, 1982) and its consequences in the form of teaching employed by the architect professor. This work aims to discuss this issue by presenting three educational exercises, looking for a more sensible route to the teaching and learning of students and teachers. The research environment within the Architecture and Urbanism courses, under the bias of the Social Imaginary, contributed to increased self-confidence of students and teachers, as well as allowed a creative interaction between teachers and students.

Keywords: Teacher Training. Architecture. Social Imagination. Creative Processes. Teaching.

RESUMEN: La arquitectura está constituida por entre el arte y el diálogo técnico: el primero es más intenso en el inicio del proceso de diseño arquitectónico, desde el mundo de las ideas; y la segunda es esencial para la materialización del objeto creado al final del proceso. A pesar de tener el saber sensible a permear todos los actos proyectivos, en la enseñanza al énfasis de los conocimientos técnicos es indiscutible $\mathrm{y}$, a menudo incuestionable. En este sentido, este artículo argumenta sobre la importancia del arte en la Ley de creación arquitectónica - en el entorno universitario - de la clase bajo la desviación del imaginario social (CASTORIADIS, 1982) y sus consecuencias en la toma de arquitecto enseñanza. A través de la presentación de tres ejercicios didácticos (incentivos creativos), llevó a cabo con los estudiantes en el primer año de Arquitectura y Planificación Urbana, tiene como objetivo problematizar el tema en busca de una ruta más sensible para la enseñanza y el aprendizaje entre los estudiantes y profesores. Se hace hincapié en que la creación de un entorno de investigación en el curso de la arquitectura y el urbanismo, bajo el empuje del Imaginario Social, además de ser un facilitador para el proceso de la creación contribuye a aumentar la confianza de los estudiantes y profesores. Por último, proporciona una acción docente fundada y formada por medio de una interacción creativa y sensible entre profesores y estudiantes.

Palabras-clave: Formación del Profesorado. Arquitectura. Imaginario Social. Procesos Creativos. Educación. 
* Arquiteta, Urbanista e Mestre em Arquitetura e Urbanismo. Professora Adjunta no Departamento de Arquitetura e Urbanismo na Universidade Federal de Santa Maria (UFSM), em Santa Maria/RS.

** Doutora em Educação. Professora Titular no Departamento de Fundamentos da Educação, coordenadora do Grupo de Estudos e Pesquisas em Educação e Imaginário Social (Gepeis), na Universidade Federal de Santa Maria (UFSM), em Santa Maria/RS.

*** Educadora Especial. Mestre em Educação, doutoranda em Educação.

\footnotetext{
${ }^{1}$ Em 1957, Jacques Tati iniciou a realização de "Meu tio", considerado o seu filme mais lírico e que se transformou em um grande sucesso mundial. O filme foi apresentado, em estreia mundial, em 9 de maio de 1958 no XI Festival de Cannes, que lhe atribuiu o Prêmio Especial do Júri; posteriormente, recebendo consagração mundial ao conquistar o Oscar de melhor Filme Estrangeiro em 1959 (CINE FRANCE, 2015).
}

\section{DESAFIO: NA ARTE ASSIM COMO NA TÉCNICA}

\begin{abstract}
[...] ainda consigo sentir na minha mão a maçaneta do portão, esta peça de metal moldada como as costas de uma colher. Tocava nela quando entrava no jardim da minha tia. Esta maçaneta ainda hoje me parece um sinal especial de entrada num mundo de ambientes e cheiros diversos [...]. (ZUMTHOR, 2009).
\end{abstract}

Os desenhos da execução técnica de um projeto arquitetônico são específicos e objetivos, exprimem certeza e confiança. São feitos por técnicos para outros técnicos que materializarão o objeto criado. Não procuram convencer e cativar como os desenhos iniciais do projeto, os primeiros rabiscos. Para uma obra ser construída são necessários critérios racionais e objetivos. Mas, o ato de projetar é baralhado por ideias subjetivas, não refletidas, e coberto por sentimentos pessoais (ZUMTHOR, 2009).

Desde o primeiro estímulo, interno ou externo, este ato, o da criação, acompanha o criador até os desenhos de execução técnica. Mas é no início, bem no início, ainda no mundo das ideias, que a criatividade parece borbulhar. No contexto da universidade o aluno de arquitetura e urbanismo é o ator principal e o professor arquiteto, o coadjuvante. A sensibilidade permeia ambos os fazeres, tanto na concepção do objeto, do edifício, quanto na capacidade do docente de estimular a criação e aproximar o estudante da esfera artística.

As discussões acerca da arquitetura permeiam o universo da arte e da técnica, em uma dialética entre emoção e razão. Contudo, quase sempre, o paradigma racionalista se sobressai e a arquitetura mostra-se cartesiana, objetiva e distante da área criativa que se propõe em uma conjuntura onde há pouca discussão sobre as questões relativas ao mundo das ideias e onde o docente, quase sempre, prefere o caminho seguro da técnica, em uma abordagem pragmática, ficando o aluno do Curso de Arquitetura à mercê do talento.

Essa abordagem pragmática do fazer arquitetônico, na história da arquitetura, foi reforçada pelo Movimento Modernista. Ábalos (2008) escreve que a casa moderna representa o paradigma positivista de salvação, de solução para todos os problemas, por meio do desenvolvimento técnico e científico. O homem que habita o edifício moderno tem fé no futuro e acredita que o avanço tecnológico trará ordem e progresso. O filme Mon Oncle (Meu Tio) - do diretor Jacques Tati' ${ }^{1}$, realizado em 1957 -, conforme menciona Ábalos, ilustra bem essas crenças.

Duas casas são apresentadas no filme, a primeira é a casa do tio, localizada em um bairro antigo da velha Paris, onde a desordem e o caos prevalecem (Figura 1). A segunda é uma casa moderna, localizada em um bairro novo e distante do centro histórico, propriedade de um rico industrial, e é símbolo de ordem, de higiene e tecnologia (Figura 2). 
Embora o ambiente moderno seja organizado e belo, todos, no filme, parecem preferir o bairro antigo com suas construções caóticas.

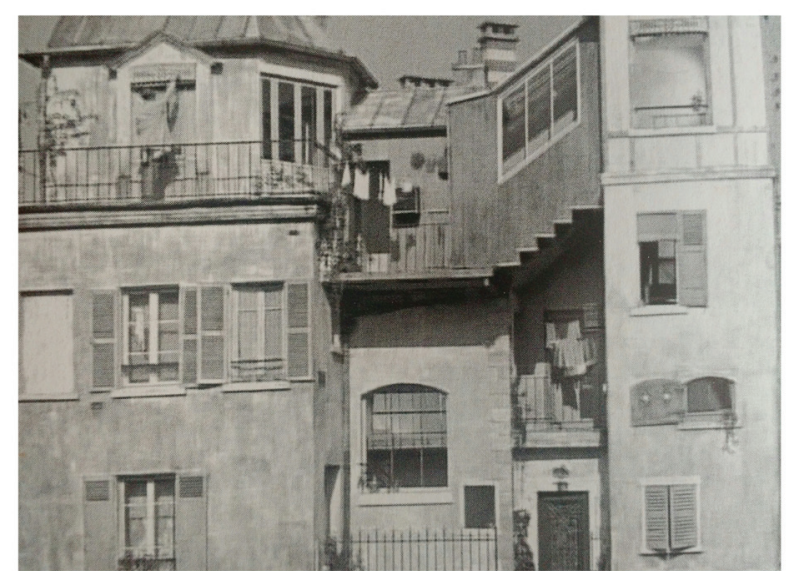

Figura 1 - Casa do tio no subúrbio, Filme MonOncle. Fonte: Ábalos (2008).

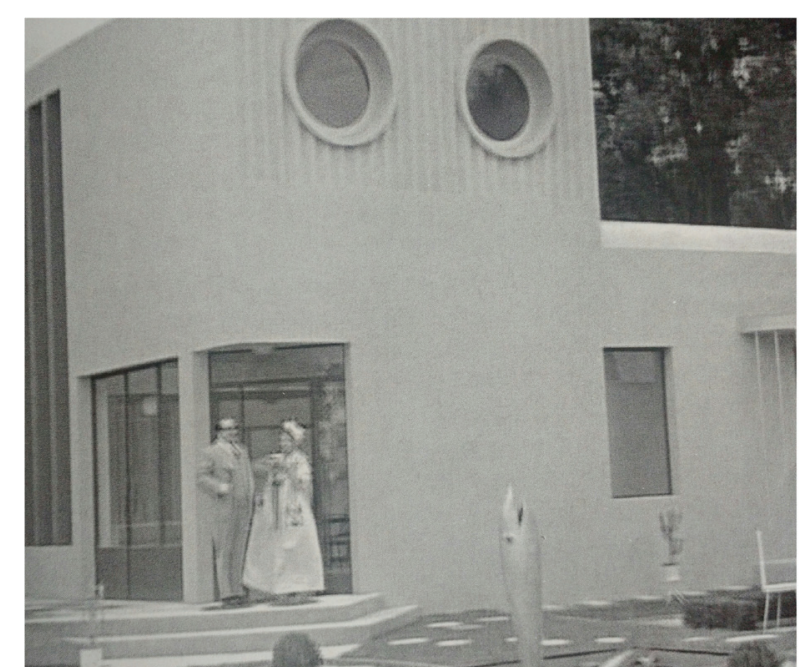

Figura 2 - Casa moderna, Filme MonOncle.

Fonte: Ábalos (2008).

Há uma espontaneidade nas pessoas ao circularem pelas ruas estreitas e aparentemente sujas da velha Paris, mas que não existe no contexto ordenado da casa moderna que parece ditar regras e comportamentos. Na conjuntura do Movimento Moderno, os arquitetos acreditavam na solução dos problemas sociais por meio da construção de edifícios que prezavam pela insolação, iluminação, mecanização e inovações tecnológicas. Não obstante a importância do Movimento Moderno para a arquitetura, o viés positivista impõe uma padronização do homem e dos problemas relativos ao projeto, e as características individuais, tanto do arquiteto como do usuário, são secundárias. Esse olhar positivista para o projeto reforçou, desde o início do século XX, uma abordagem da arquitetura como ciência racional e tecnológica; desse modo, as discussões sobre a esfera criativa, na maioria das vezes, acabam ficando fora dos debates. 
Além da influência do Movimento Moderno, contribui para o fazer pragmático do professor arquiteto a "naturalização da docência”, a qual - segundo Cunha (2006) - se refere à manutenção dos processos de reprodução cultural, visto que o professor ensina a partir da sua experiência como aluno, inspirado em seus antigos professores.

[...] todos os professores foram alunos de outros professores e viveram as mediações de valores e práticas pedagógicas. Absorveram visões de mundo, concepções epistemológicas, posições políticas e experiências didáticas. Através delas, foram se formando e organizando, de forma consciente ou não, seus esquemas cognitivos e afetivos, que acabam dando suporte para a sua futura docência [...]. (CUNHA, 2006, p. 259).

Assim, no decorrer do tempo, reforçaram-se os saberes técnicos, advindos principalmente do mercado de trabalho. O professor arquiteto reproduz no contexto da sala de aula sua experiência profissional, ficando os saberes pedagógicos e consequentemente, os sensíveis, à mercê da boa vontade de alguns profissionais. No dizer de Castoriadis (1982) somos levados a pensar de que forma incentivamos que o estudante, sujeito de uma sociedade, pense o espaço que habita relacionado ao que é levado a pensar.

A apresentação do resultado como totalidade sistemática e burilada, o que na verdade ele nunca é; ou mesmo do processo de construção - como é tão freqüente [sic] o caso, pedagógica mas, falaciosamente, de tantas obras filosóficas - sob a forma de processo lógico ordenado e controlado, só reforça no leitor a ilusão nefasta para a qual ele, como todos nós, já tende naturalmente, de que o edifício foi construído para ele e doravante basta habitá-lo se assim lhe apraz. (CASTORIADIS, 1982, p. 12).

Diante dessa atuação docente, a esfera artística, muitas vezes, apresenta-se como algo distante, como dádiva aos escolhidos - como dom, para os estudantes de arquitetura e, consequentemente, para muitos arquitetos. Nesse sentido, o docente, no Curso de Arquitetura e Urbanismo, deve fazer alguns questionamentos, tais como: quais os meios para alcançar a criatividade? Como aproximar os alunos da arte, na arquitetura? Como eu, professor, lido com o mundo sensível no universo arquitetônico? Esses questionamentos motivaram a realização das atividades descritas neste trabalho, que estão balizadas na valorização das experiências pessoais, fundamentas no campo teórico do Imaginário Social (CASTORIADIS, 1982).

Para Zumthor (2009), fazer arquitetura significa colocar questões a si próprio, significa encontrar a própria resposta com o apoio do professor. Nas primeiras 
vivências, estão as raízes do entendimento arquitetônico: no nosso quarto, na nossa casa ou na nossa cidade; enfim, na nossa biografia. Assim, os estudantes podem aprender a trabalhar de forma consciente as suas experiências pessoais. E a tarefa de projetar deve desencadear esse processo de investigação, que é um trabalho de memória. Logo, faz parte desse processo mental a produção de imagens interiores que constitui um pensar em imagens, que é um método de projetar.

Portanto, com a instituição de um saber sensível no ambiente da sala de aula, alunos e professores podem aproximar-se da arte tão fundamental para a arquitetura. Para o docente, esse cotidiano mais artístico também constitui seu saber pedagógico. E, no campo do Imaginário Social, onde vivências e memórias são fundamentais, mostra-se imprescindível para sua formação.

\section{ENCONTRO: A POÉTICA DO IMAGINÁRIO}

Na contemporaneidade, principalmente com a utilização da internet, o excesso de frivolidade da informação imagética coloca em pauta a necessidade de uma postura mais crítica diante do fazer arquitetônico. A valorização de modelos arquitetônicos cada vez mais padronizados, e muitas vezes inspirados em edifícios publicados em revistas especializadas, incentiva discussões acerca da abordagem de projeto como uma simples questão de imagens referenciais.

Segundo Pimenta, Anastasiou e Cavallet (2003), os avanços tecnológicos, as novas configurações do trabalho e da produção, configuram a sociedade da informação e do conhecimento. A informação é o primeiro estágio do conhecimento e conhecer implica classificar, analisar e contextualizar as informações. Há um terceiro estágio que envolve a inteligência, a consciência ou sabedoria e se constitui na habilidade de vincular o conhecimento de maneira útil, exigindo reflexão.

[...] no entanto, se entendemos que conhecer não se reduz a se informar, que não basta se expor aos meios de informação para adquiri-la, senão que é preciso operar com as informações na direção de, a partir delas, chegar ao conhecimento, então parece-nos que a Universidade (e os professores) tem um grande trabalho a realizar, que é proceder à mediação entre a sociedade da informação e os alunos, para possibilitar que, pelo exercício da reflexão, adquiram a sabedoria necessária à permanente construção do humano. (PIMENTA; ANASTASIOU; CAVALLET, 1996, p. 102).

Nesse contexto, onde o aluno encontra-se submerso por informações, cabe ao professor incentivar uma postura mais crítica, promovida pelo conhecimento e pela reflexão. 
Instigar o aluno encorajando-o a se aventurar no próprio universo pode facilitar o ato da criação e o desenvolvimento cognitivo mediante uma compreensão mais ampla do fazer arquitetônico e, por conseguinte, do próprio objeto. Nesse caminho de interiorização, os estudos do Imaginário Social constituem ferramentas possíveis para o criar, para o encontro do saber sensível.

Castoriadis (2004) assevera que o imaginário do ser humano singular constitui uma potência de criação; afinal, nele está a determinação essencial da psique humana. Essa psique é a imaginação radical, é fluxo incessante de representações, desejos, afetos. É inútil fechar os olhos ou tapar os ouvidos, porque é algo que se passa no mundo interno, "dentro" - imagens, lembranças, desejos, temores etc. E esses elementos não são ligados entre si de maneira racional e, muitas vezes, são representações sem nenhuma funcionalidade.

Portanto, a imaginação humana é descontrolada, cria formas e conteúdo que não correspondem a nenhuma necessidade. De acordo com a definição de imaginário radical, a criação é espontânea e gratuita e, na dimensão do outro, é inalcançável. Cada indivíduo tem seu mundo próprio e existe através de um fechamento. Então, como alcançar esse mundo distante e imaginário do outro? O autor ressalta que não podemos entrar no mundo do outro, mas podemos dar-lhe choques e nos colocarmos em seu lugar, sempre conscientes de que cada um reagirá ao seu modo (CASTORIADIS, 2004). Na vida em sociedade, a imaginação radical precisa ser trabalhada.

[...] É preciso, portanto, que essa imaginação radical dos seres humanos seja domada, canalizada, regulada, adequando-se à vida em sociedade e também ao que chamamos de realidade. Isso se faz por intermédio de sua socialização, durante a qual eles absorvem a instituição da sociedade e suas significações, interiorizam-nas, aprendem a linguagem, a categorização das coisas, o que é justo e injusto, o que se pode fazer e o que não se deve fazer, o que se deve adorar e o que se deve odiar. (CASTORIADIS, 2004, p. 132).

Trabalhar com o universo sensível implica respeitar a subjetividade do outro. No caso da arquitetura, o mundo impar e intocável de cada um encontra o mundo do outro (colega, professor) por intermédio das discussões sobre o espaço. É o espaço o elemento organizador que chama para a realidade. Para Bachelard (2008), o espaço percebido pela imaginação não pode ser o espaço entregue à mensuração e à reflexão do geômetra. É um espaço vivido com todas as parcialidades da imaginação.

Neste sentido, em uma simbiose entre o espaço do geômetra e o espaço vivido pela imaginação, o ser que cria na arquitetura organiza suas ideias, encontra um caminho, um diálogo com o mundo em sociedade. Assim, 
compreende-se que o pensar racional auxilia na sistematização das ideias; porém, o ato poético, no devir das imagens, é subjetivo e, para Bachelard (2008), é súbito realce do psiquismo. A explosão de uma imagem, para esse autor, causa ressonâncias e repercussões que convidam a um aprofundamento da própria existência. Essas ressonâncias e repercussões encontram um ambiente profícuo na sala de aula, na interação entre estudantes de arquitetura e professores arquitetos, mediada por uma abordagem sensível sob o viés do universo das imagens, do mundo das ideias.

\section{DO SIGNIFICADO DAS PALAVRAS: ALGUMAS VIVÊNCIAS CRIATIVAS}

A partir da problemática colocada, três exercícios são descritos neste artigo de modo a enriquecer as discussões pretendidas. São exercícios de caráter exploratório, que tratam do processo de materialização da forma, empregando como elemento indutor da criação uma palavra, um conceito. Configuram-se como experimentações, ferramentas facilitadoras no processo de criação e evolução das ideias que valorizam o indivíduo e sua subjetividade. Esses exercícios foram realizados por alunos que cursavam o primeiro ano do curso de Arquitetura e Urbanismo inseridos dentro de disciplinas ou dentro do ambiente de pesquisa.

Desconstruir alguns dos conceitos dados culturalmente é função de um espaço de formação profissional quando se acredita que, para além do fazer técnico, há um fazer sensível propondo a revitalização dos ambientes que ocupamos. Se fragmentados são os espaços conceituais, também permanecem assim nas estruturas de sociedade que permearem o fazer técnico; logo, teremos construções frias. No entanto, repensando o fazer pedagógico na formação profissional, é possível mexer com a existência de um indivíduo que queira habitar espaços mais sensíveis.

Os indivíduos socializados são fragmentados ambulantes e falantes de uma sociedade dada; e são fragmentados totais; isto é, encarnam, em parte efetivamente, em parte potencialmente, o núcleo essencial das instituições e das significações de sua sociedade; o indivíduo é uma criação social, tanto como tal, quanto em sua forma social-histórica a cada vez dada. (CASTORIADIS, 1999, p. 280).

Por ser tratar do universo da arquitetura, foram escolhidas palavras que podem ser traduzidas, materializadas, em uma forma representando um conceito, uma característica que se evidencia. Do mundo das ideias, das imagens, à materialização, parte-se do princípio que cada palavra pode ser descrita, sintetizada, de maneiras diversas, assim como cada signo criado (objeto, espaço ou texto) pode apresentar significados para além da palavra trabalhada. Desse modo, a palavra é o incentivo e também o través do ato da criação. 


\subsection{Exercício 1: as palavras e a forma}

A primeira atividade ocorreu junto a um projeto de pesquisa, ocasião em que o aluno definiu quatro palavras para estudar (envolvimento, flexibilidade, fluidez e fragmentação). No primeiro momento, os seguintes itens foram pesquisados com o objetivo de ampliar o significado da palavra: definição geral da palavra, definição da palavra na arquitetura e exemplos de projetos, mundialmente reconhecidos, e que, de alguma maneira expressassem o conceito - na organização espacial, nos materiais, na forma, na espacialidade etc.Embora a criatividade esteja implícita em todo processo, foi na segunda etapa que aconteceu a exploração dos conceitos, das palavras, através da forma com a utilização de maquetes físicas. A meta era criar formas que se configurassem como símbolos das palavras. Todo processo de criação foi registrado pelo aluno, desde o surgimento das primeiras ideias e imagens até as dificuldades para fazer as maquetes.

Para ilustrar, seguem duas maquetes criadas (Figura 3 e Figura 4), baseadas em duas palavras distintas, acompanhadas das imagens mentais, associações, descritas pelo aluno:

\subsubsection{Palavra Envolvimento}

As tempestades caminham até se chocarem e, por diferença de temperatura, produzem ventos que se movimentam em diferentes direções, que carregam e envolvem tudo, em grandes velocidades. (Descrição do aluno, 2011).

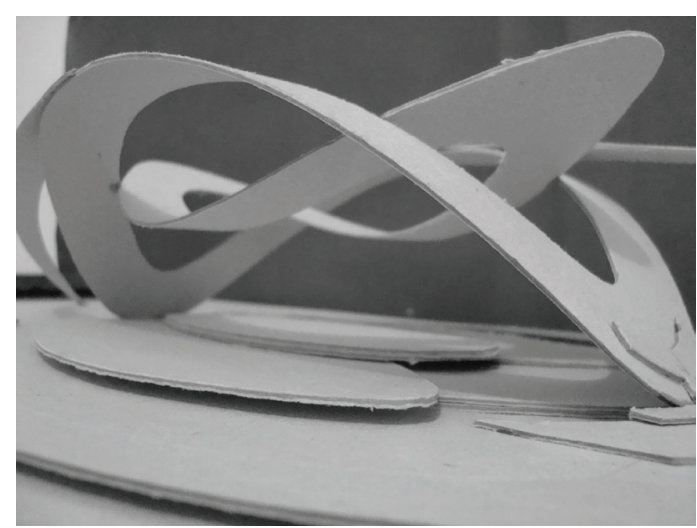

Figura 3 - Maquete do envolvimento Fonte: Arquivo pessoal (2011).

\subsubsection{Palavra Fragmentação}

O tempo é algo fragmentado. Os seres humanos percebem o tempo no momento em que quantificam os diferentes eventos que acontecem. Para se estabelecer e organizar o tempo, criou-se o tempo cronológico. O tempo, para cada indivíduo, se altera conforme, nunca é igual, é um reflexo das experiências vividas. (Descrição do aluno, 2011). 


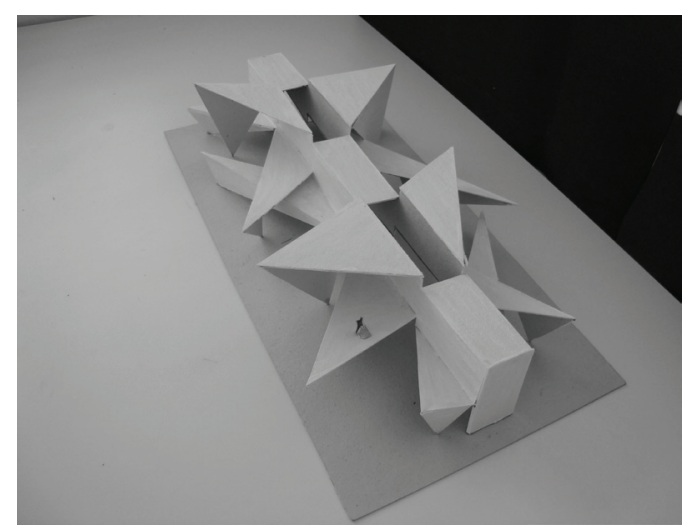

Figura 4 - Maquete da fragmentação Fonte: Arquivo pessoal (2011).

Quanto ao Imaginário, as maquetes foram criadas a partir das analogias, das primeiras imagens que surgiram. Esse processo valoriza a vivência do aluno que busca, em suas memórias, respostas para o problema colocado através de associações que facilitam o ato, o processo de criação. E qual a relação das primeiras ideias, das primeiras imagens, com o símbolo criado?

Cada maquete criada ilustra uma possibilidade, um caminho. $\mathrm{O}$ aluno relatou que o fato de uma simples palavra transmitir as mais variadas sensações e significações por meio da forma de um objeto o surpreendeu, principalmente devido à infinidade de possibilidades. Durante o processo, não existe certo e errado e muitas ideias são descartadas pelo caminho. Ao professor, cabe respeitar a individualidade de cada aluno, deixando-o livre para fazer alterações, ver possibilidades e fazer escolhas e o desafio de estimular o aluno sem tomar as decisões por ele.

\subsection{Exercício 2: as palavras e o espaço}

O segundo exercício ocorreu em sala de aula, na disciplina de Ateliê de Projeto - que é dividida em três módulos: no primeiro módulo, há uma aproximação à comunidade com a leitura e análise de um bairro; no segundo, ocorre a definição, o estudo e a exploração de um conceito através de uma palavra; no terceiro, desenvolve-se o anteprojeto arquitetônico e paisagístico de um centro comunitário, localizado no bairro estudado no módulo um, tendo como referência o conceito definido no módulo dois. O exercício a ser apresentado diz respeito ao módulo dois, desenvolvimento conceitual, cujo objetivo era criar um espaço, uma instalação em escala 1:1 que simbolizasse uma palavra.

Na instalação, os significados da palavra podem estar presentes na forma, nos materiais escolhidos, na estrutura, na organização de ambientes, na ambiência, ou no percurso do visitante, cabendo à equipe explorar as sensações e vivências que aspira propiciar. É um trabalho de criação coletiva. O trecho a seguir descreve as intenções de uma equipe que trabalhou com as palavras robustez e leveza e criou um moinho (Figura 5 e Figura 6): 
O espaço criado foi pensando para o usuário interagir ao adentrar, assimilar, através dos sentidos, a ideia do que é robusto, em oposição ao que é entendido por leveza. A parte inferior do moinho, a base, exalta força, solidez e estabilidade, o que está intimamente ligado ao caráter robusto. Enquanto sua parte superior formada pelas pás sensíveis ao leve sopro, depende do ar, de um fluxo de gases invisíveis ao olho nu, constitui uma ideia totalmente ligada à leveza. Ao adentrá-lo, havia duas alavancas que, ao serem aplicadas forças de giro, acarretavam o movimento das pás do moinho. Assim, o usuário podia vivenciar a relação de oposição presente no moinho através da força braçal aplicada que movimenta as pás num efeito esvoaçante e leve. (Descrição da equipe, 2014).

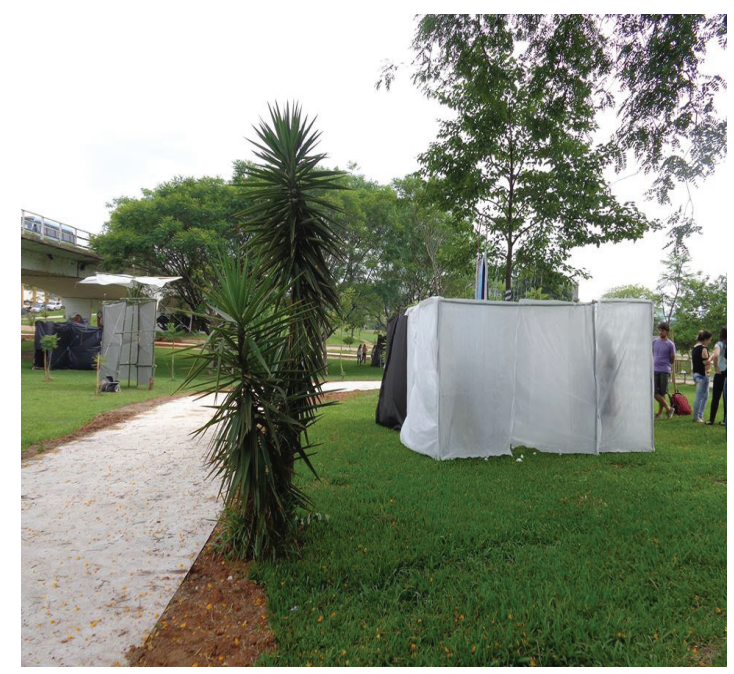

Figura 5 - Moinho da Robustez e Leveza. Fonte: Arquivo pessoal (2015).

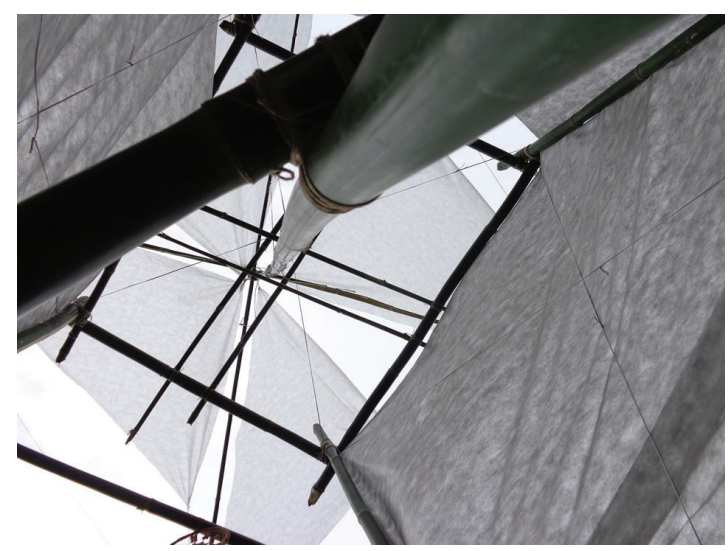

Figura 6 - Moinho da Robustez e Leveza Fonte: Arquivo pessoal (2015).

Esta prática permitiu aos estudantes uma aproximação com o conceito pela vivência do espaço. Nesse contexto, é mais fácil perceber que cabe ao projetista explorar os sentidos humanos para além do mais explorado, a visão. No caso do moinho da robustez e leveza, o projeto interagiu bem 
com o meio inserido, expressando um contraste de significados, propiciando uma interação rica entre os usuários e o espaço gerado.

No viés do Imaginário, o moinho (criação coletiva) é uma síntese que representa um pouco do universo de cada membro da equipe. Nesse sentido, a criação percorreu um caminho mais longo que partiu do mundo das ideias de cada indivíduo e passou por momentos de discussão coletiva que configuraram balizadores para as tomadas de decisões.

\subsection{Exercício 3: as palavras e o texto}

Essa dinâmica foi proposta para alunos de um grupo de estudos cujo objetivo principal é vivenciar experiências e discussões que tratam do processo de criação. 11 alunos participaram da atividade e tinham como objetivo a materialização de uma palavra conceito através de um texto. Como desafio, em seus textos, deveriam fazer referências a algum espaço do Curso de Arquitetura e Urbanismo. Seguem alguns trechos dos textos criados:

\subsubsection{Trecho 1: sobre a palavra Contraste}

[...] A sala baixa e escura sufoca. A porta é pequena. Não tem janelas. O sol não entra. A sala está presa em um dia cinza. Seja noite, seja dia, às $14 \mathrm{~h} 45 \mathrm{~min}$, às $03 \mathrm{~h}$ : cinza, tudo cinza. Não há contraste. Não há vida. Está sempre escuro, exceto pela luminosidade que vem de fora nas poucas vezes em que a porta está aberta. Um espaço tão carente de vida, contrapondo-se ao grande espaço aberto do hall alto, iluminado e cheio de sons [...]. (ALUNO 1, 2015).

\subsubsection{Trecho 2: sobre a palavra Fragmentação}

[...] Todos se sentam, quietos, com um ar macabro, como de um sótão de uma casa antiga, habitada por fantasmas e espíritos guardiões de segredos e mistérios de várias gerações. Mas logo alguém entra nesse ambiente, modificando toda aquela sensação de vazio, e começa a fragmentar todos os conceitos, a doutrina, os fundamentos da arquitetura em partes bem pequenas, triviais, que aos poucos, somadas entre si, formas sentido e importância [...]. (ALUNO 2, 2015).

A materialização da palavra através de textos foi um desafio diferente para os alunos que estavam acostumados a pensar a materialização através da forma e do espaço. A dinâmica mostrou-se um exercício muito profícuo, onde todos se sentiram estimulados a criar. Para o docente arquiteto, constituiu-se como convite para deslumbrar outras possibilidades de interação com os alunos. 


\subsection{Uma reflexão sobre os exercícios e o fazer docente}

Pimenta, Anastasiou e Cavallet (2003, p. 271) enfatizam que o professor universitário - como profissional que realiza um serviço à sociedade - precisa atuar como profissional crítico, competente e capaz de realizar atividades de investigação. No aperfeiçoamento da docência universitária, a integração de saberes é importante, para além do domínio restrito de uma área científica. Assim, o saber pedagógico e o saber político possibilitam ao docente a construção da consciência de sociedade (CASTORIADIS, 1999) indo ao encontro da formação de sujeitos da educação conscientes. Logo, o presente trabalho também destaca a importância do saber sensível no fazer arquitetônico e, consequentemente, para a formação dos professores arquitetos.

A integração de saberes vem ao encontro da naturalização da profissão. Na visão de Cunha (2006), cabe sempre ao docente questionar suas verdades e práticas pela reflexão, visto que os sujeitos professores somente[...] alteram suas práticas quando são capazes de refletir sobre si e sobre sua formação. A desconstrução é um processo em que se pode decompor a história de vida, identificando as mediações fundamentais, para recompor uma ação educativa e profissional consequente e fundamentada. (p. 259).

Portanto, somente a reprodução dos saberes tecnológicos não garante uma vivência plena da arquitetura na sua definição como arte e técnica. Bachelard (2008) defende que o domínio de métodos racionais e científicos é insuficiente para compreensão do universo das imagens, do mundo de onde surgem as ideias.

[...] esse método, que tem a seu favor a prudência científica, pareceu-me insuficiente para fundar uma metafísica da imaginação. Por si só, a atitude "prudente" não será uma recusa em obedecer à dinâmica imediata da imagem? Tínhamos, aliás, verificado como é difícil libertar-nos dessa "prudência". Dizer que abandonamos hábitos intelectuais é uma declaração fácil, mas como cumpri-la? Há aí, para um racionalista, um pequeno drama diário, uma espécie de desdobramento do pensamento que, por mais parcial que seja o seu objeto - uma simples imagem - não deixa de ter uma grande repercussão psíquica. (BACHELARD, 2008, p. 3).

Nesse contexto de repercussões, os exercícios apresentados mostraram-se ferramentas facilitadoras no processo de criação e evolução das ideias dos alunos de arquitetura e eficazes enquanto estímulos, ao "dar choques", às quais Castoriadis (2004) se refere. O desafio da materialização das palavras desencadeou um borbulhar de imagens que remete à imagem poética de Bachelard, incentivando, 
assim, uma criatividade do ser falante e a revelação de uma consciência imaginante.

\section{CONCLUSÃo}

Os estudos sobre o Imaginário Social contribuíram para a aproximação da arquitetura com a esfera artística que a mesma se propõe, sobretudo pela valorização do indivíduo e de suas vivências no processo de criação. Pensar que há uma sociedade que se institui segundo as regras que ela mesma estabelece nos induz a pensar na viabilidade de repensar a formação que leva para os espaços acadêmicos, lugares que dão diretrizes para a formação profissional.

No que se refere à formação docente, o ambiente de reflexão criado em sala de aula não somente desencadeou o enriquecimento dos saberes como também incentivou uma postura projetual mais crítica, que se estendeu aos alunos, agregando, na sua íntegra, os preceitos de originalidade, criatividade e inovação. Nesse contexto, os imaginários de Castoriadis e Bachelard foram reunidos em prol do desenvolvimento de uma criação instituinte e do devaneio poético na formação dos docentes e futuros arquitetos.

\section{REFERÊNCIAS}

ÁBALOS, Iñaki. A Boa-vida: visita guiada às casas da modernidade. Barcelona: Gustavo Gili, 2008.

BACHELARD, Gaston. A Poética do Espaço. São Paulo: Martins Fontes, 2008.

CASTORIADIS, Cornelius. A instituição imaginária da sociedade. Tradução de Guy Reynaud. Rio de Janeiro: Paz e Terra, 1982.

CASTORIADIS, Cornelius. As encruzilhadas do labirinto V. Feito e a ser feito. Tradução de Lílian do Valle. Rio de Janeiro: DP\&A, 1999.

CASTORIADIS, Cornelius. Figuras do Pensável: as Encruzilhadas do Labirinto - Volume VI. Tradução de Eliana Aguiar. Rio de Janeiro: Civilização Brasileira, 2004.

CINE FRANCE. Jacques Tati - Biografia. 2015. Disponível em: <http://www.cinefrance.com.br/filmes/profissionais/jacques-tati>. Acesso em: 12 jun. 2015.

CUNHA, Maria Isabel da. Docência na universidade, cultura e avaliação institucional: saberes silenciados em questão. Revista Brasileira de Educação, v. 11, n. 32, p. 258-371, maio/ago. 2006.

PIMENTA, Selma Garrido; ANASTASIOU, Léa das Graças; CAVALLET, Valdo José. Docência no ensino superior: 
183 O IMAGINÁRIO DA PALAVRARIA: UM CAMINHO PARA O DOCENTE VIVENCIAR A ESFERA ARTÍSTICA QUE A ARQUITETURA PROPÕE

construindo caminhos. In: BARBOSA, Raquel Lazzari Leite. Formação de educadores: desafios e perspectivas. São Paulo: Editora UNESP, 2003. p. 268-296.

ZUMTHOR, Peter. Pensar a Arquitectura. Barcelona: Gustavo Gili, 2009.

Recebido em: 12/04/2016 Aprovado em: 02/09/2016 